\title{
O ensino de matemática e tecnologias: ações e perspectivas de professores de matemática em tempo de pandemia
}

\author{
Teaching mathematics and technologies: actions and perspectives of mathematics \\ teachers in pandemic
}

\author{
Enseñanza de las matemáticas y las tecnologías: acciones y perspectivas de los \\ profesores de matemáticas en tiempos de pandemia
}

\begin{abstract}
Maria Cristina Rosa ${ }^{1}$
José Elyton Batista dos Santos ${ }^{2}$

Denize da Silva Souza ${ }^{3}$

\section{Resumo}

Este trabalho apresenta o resultado de um estudo, que teve objetivo conhecer como as ações de enfrentamento à pandemia têm implicado no exercício da docência de professores de matemática, sobretudo, em relação à inserção das tecnologias de informação e comunicação (TIC). Como estratégias metodológicas, foi elaborado um questionário online disponibilizado aos participantes por meio da plataforma SurveyMonkey, obtendo respostas de 22 professores

\footnotetext{
${ }^{1}$ Mestre em Ensino de Ciências e Matemática pela Universidade Federal de Sergipe (NPGECIMA/UFS). Possui Licenciatura em Matemática pela Universidade Alto Vale do Rio do Peixe (UNIARP), com especialização em Práticas interdisciplinares no ensino de matemática pela Faculdade de Ensino Superior Dom Bosco e Licenciatura em Física pela Universidade do Extremo Sul Catarinense (UNESC). Atualmente é pesquisadora no Núcleo Colaborativo de Prática e Pesquisa em Educação Matemática da Universidade Federal de Sergipe (NCPPEM/CNPq/UFS); Professora de Matemática na rede estadual de educação do estado de Sergipe. (SEDUC/SE). Email: mariacristina.rs@ hotmail.com. ORCID: https://orcid.org/0000-0001-5986-7846

${ }^{2}$ Doutorando em Educação pelo Programa de Pós-Graduação em Educação da Universidade Federal de Sergipe. Mestre em Ensino de Ciências e Matemática pela Universidade Federal de Sergipe (2018). Licenciado em Matemática pela Universidade Federal de Alagoas - UFAL (2014) e licenciado em Pedagogia pelo Centro Universitário Internacional UNINTER (2020). Especialista em Metodologia do Ensino da Matemática e Física pelo Centro Universitário Internacional - UNINTER (2015) e especialista em Educação Infantil e Anos Iniciais pela Faculdade Venda Nova do Imigrante - FAVENI (2019). Integrante dos grupos de pesquisas: Núcleo Colaborativo de Práticas e Pesquisas em Educação Matemática (NCPPEM/UFS) e Grupo de Estudos em Educação Superior (GEES). Professor de Matemática da Educação Básica e no Ensino Superior. Email: elyton batista@hotmail.com. ORCID: https://orcid.org/0000-0003-1763-8134

${ }^{3}$ Doutora em Educação Matemática pela Universidade Anhanguera de São Paulo. Mestre em Educação pela Universidade Federal de Sergipe. Especialista em Arteterapia pela FIZO-ALQUIMYART e Licenciada em Matemática pela Universidade Federal de Sergipe. É professora da Universidade Federal de Sergipe no Departamento de Matemática (Campus São Cristóvão) e no Programa de Pós-Graduação em Ensino de Ciências e Matemática (PPGECIMA/UFS). Pesquisadora do Grupo de Estudos e Pesquisa em Educação e Contemporaneidade (EDUCON/UFS); Vice-líder do Núcleo de Estudo, Extensão e Pesquisa em Inclusão Educacional e Tecnologia Assistiva (NÚPITA/UFS, sendo mediadora do sub-eixo temático Matemática Inclusiva) e Líder do Núcleo Colaborativo de Práticas e Pesquisas em Educação Matemática (NCPPEM/UFS). Tem experiência em formação de professores, com ênfase em Educação Matemática, atuando também com outros temas: Universo Explicativo; Relação com o Saber; Didática da Matemática; Educação Inclusiva; Currículo; Ensino e aprendizagem em geometria. Foi coordenadora da área de Matemática do PIBID/UFS (2014 - 2018); coordenadora de Projetos de Pesquisa "Análise praxeológica de conteúdos geométricos em livros didáticos de matemática à luz de diagramas esquemáticos" PIBIC/COPES/UFS, no período 2016-2018) e foi coordenadora de área do Programa Residência Pedagógica - RP/Matemática/SC (UFS - 2018-2020). Atualmente coordena o Projeto de Oficinas de Matemática: somando conhecimentos, multiplicando saberes para professores que ensinam matemática em redes municipais de Sergipe e do Projeto de Pesquisa intitulado Objetos ostensivos e não ostensivos em praxeologias matemáticas acerca de conteúdos geométricos. Email: denize.souza@ hotmail.com. ORCID: http://orcid.org/0000-0002-4976-893X
} 
de matemática da educação básica, nos estados de Sergipe, Alagoas e Bahia. Como apoio teórico para análise dos dados, foram utilizados os documentos de orientações nacionais, destinados a regulamentar as aulas da educação básica neste período de aulas remotas, além de estudos desenvolvidos por pesquisadores da educação matemática, que apontam direcionamentos acerca da formação docente no contexto da inserção das TIC em ambientes educacionais. Como resultados, os professores evidenciam dois principais obstáculos a serem superados nos processos de ensino e aprendizagem durante esse período; a pouca interação com os alunos, e a defasagem na sua formação docente para o uso das TIC. Em vista disso, como estratégias para superar esses desafios, os professores apontam uma reorganização didática-pedagógica, priorizando abordagens que minimizem tais dificuldades.

Palavras-Chave: Ensino de matemática; TIC; professores de matemática; aulas remotas.

\begin{abstract}
This work presents the result of a study, which aimed to find out how the actions to combat the pandemic have implied teaching mathematics teachers, especially in relation to the insertion of information and communication technologies (ICT). As methodological strategies, an online questionnaire was made available to participants through the SurveyMonkey platform, obtaining answers from 22 mathematics teachers from basic education, in the states of Sergipe, Alagoas and Bahia. As theoretical support for data analysis, the documents of national guidelines were used, aimed at regulating basic education classes in this period of remote classes, in addition to studies developed by researchers in mathematics education, which point out directions about teacher training in the context of education. insertion of ICT in educational environments. As a result, teachers show two main obstacles to be overcome in the teaching and learning processes during this period; little interaction with students, and the gap in their teacher training for the use of ICT. In view of this, as strategies to overcome these challenges, teachers point to a didactic-pedagogical reorganization, prioritizing approaches that minimize such difficulties.
\end{abstract}

Keywords: Math teaching; ICT; math teachers; remote classes.

\title{
Resumen
}

Este artículo presenta el resultado de un estudio, que tuvo como objetivo conocer cómo las acciones para combatir la pandemia han implicado en la práctica docente de los docentes de matemáticas, especialmente en relación a la inserción de tecnologías de la información y la comunicación (TIC).Como estrategias metodológicas, se puso a disposición de los participantes un cuestionario en línea a través de la plataforma SurveyMonkey, obteniendo respuestas de 22 profesores de matemáticas de educación básica en los estados de Sergipe, Alagoas y Bahía. Como soporte teórico para el análisis de datos, se utilizaron documentos de orientación nacional, orientados a regular las clases de educación básica en este período de clases a distancia, además de estudios desarrollados por investigadores en educación matemática, que apuntan a orientaciones sobre la formación docente en el contexto de inserción de TIC en entornos educativos. Como resultado, los docentes muestran dos obstáculos principales a superar en los procesos de enseñanza y aprendizaje durante este período; la poca interacción con los estudiantes y el retraso en la formación de sus profesores 
para el uso de las TIC. Ante esto, como estrategias para superar estos desafíos, los docentes apuntan a una reorganización didáctico-pedagógica, priorizando enfoques que minimicen tales dificultades.

Palabras clave: Enseñanza de las matemáticas; TIC; profesores de matemáticas; clases a distancia.

\section{Introdução}

Sabe-se que a educação está em constante transformação. Seu maior impulsor é a sociedade contemporânea que, ancorada às Tecnologias da Informação e Comunicação (TIC), suscita mudanças nas rotinas diárias ao que se refere no modo de socializar-se. Assim, também, de estudar, informar-se, aprender, estar longe e tão próximo, concomitantemente; em suma, de viver.

Com o avanço da internet tudo se tornou mais fácil e ágil. A informação está onipresente com apenas um clique. A vida não é a mesma sem um smartphone conectado a um sinal de wi-fi. Estamos conectados constantemente e não percebemos. Até mesmo desconectados, continuamos conectados, isto é, ficamos inquietos, ansiosos, esperando uma saudação, uma mensagem avisando que chegou no trabalho, que está tudo bem, dentre outras situações do nosso dia a dia.

As TIC propalaram e integraram-se rapidamente aos diferentes contextos da sociedade. Entretanto, ao que se refere ao âmbito educacional, Santos (2018) destaca que essa difusão se encontra de forma gradativa, ou seja, as tecnologias predominantes nesses recintos são livros didáticos impressos, quadro e giz. As do tipo, digitais, são utilizadas para envio de um e-mail, digitar um relatório ou diário de classe. Essa forma de manuseio, Borba, Scucuglia e Gadanidis (2015) denominam de domesticação das tecnologias.

Todavia, vivemos em um mundo de incertezas. Em um século que traz o inesperado, invés do planejado, como maior exemplo, o momento atual. Ou melhor, com a declaração da Organização Mundial da Saúde (OMS), em 11 de março de 2020, que o vírus COVID-19 encontrava-se presente em todos os continentes sendo caracterizado como pandemia (BRASIL, 2020a). O isolamento e o distanciamento se fizeram presentes como marco social e pioneiro para diversos países, entre os quais, o Brasil.

Diante dessa situação, em 17 de março de 2020, por meio da Portaria No 343/2020, o Ministério da Educação (MEC) se manifestou suspendendo as aulas presenciais e 
substituindo-as por aulas digitais (BRASIL, 2020a). Isso mudou completamente a configuração da sala de aula, as quais passaram a ser substituídas por plataformas ou ambientes virtuais de aprendizagem.

A velocidade como essas medidas foram impostas afetou as mais diversas áreas e segmentos da sociedade, sobretudo, a educação. A imprevisibilidade tem seus efeitos e consequências, e no caso dos professores, principalmente, "os que procuram caminhar numa zona de conforto onde quase tudo é conhecido, previsível e controlável” (BORBA, 2015, p. 56), implica consequentemente em todo processo - planejamento, (re)construção do conhecimento e integração adequada das tecnologias em prol do despertar, conhecer e aprender.

Desse modo, a situação exposta nos remete algumas inquietações: Como os professores estão se desdobrando e quais dificuldades estão tendo para manter a qualidade e equidade do ensino e aprendizagem em meio a uma sociedade diversa culturalmente e socialmente? Quais tecnologias estão sendo utilizadas para o novo formato de sala de aula? Quais perspectivas em relação às TIC para o ensino de matemática como instrumento contributivo e facilitador da aprendizagem?

Nesse cenário de transformação rotineira de forma vertiginosa, nota-se o quanto a educação necessita equipar-se como outros segmentos da sociedade contemporânea acerca do uso das TIC. Assim, este estudo buscará responder as questões citadas, tendo como objetivo geral conhecer e refletir como as ações de enfrentamento à pandemia têm implicado no exercício da docência dos professores de matemática, sobretudo, em relação ao processo de inserção das TIC.

\section{Tecnologias para o ensino de matemática}

Integrar as TIC no ambiente escolar ainda é um dos maiores desafios do século XXI. Embora os alunos conduzam as tecnologias aos recintos escolares, esses repelem seu respectivo uso. Ainda, para muitos professores, inserir as TIC refere-se a um "verdadeiro desequilíbrio, resistência e relutância" (ALMOULOUD, 2018, p. 207), tornando-se inadaptáveis as novas propostas para o ensino e aprendizagem.

Com a indigência da usabilidade, os professores, em sua maioria, limitam-se a aplicar estratégias de ensino próximas à realidade do aluno. Consequentemente, implica no impasse 
para uma nova formação de identidade profissional recorrente a um cenário cada vez mais digital.

\begin{abstract}
Embora ainda seja um processo de reconhecimento dos/as próprios/as docentes, os smartphones e tablets gradualmente vêm conquistando espaços nas metodologias de ensino. Devido a praticidade observada pelas novas gerações de nativos digitais inseridos na sociedade do conhecimento, surge a aprendizagem móvel, configurada em um cenário atrativo de possibilidades que a abrangência das TIC pode oferecer. (RICHTER; WUNSCH; BOTTENTUIT JUNIOR, 2020, p.15)
\end{abstract}

A usabilidade é um dos fatores que contribui para o reconhecimento das possibilidades e vantagens das TIC no ensino. Só se conhece algo quando parar para entender ou compreender seu real valor ou potencial (MORIN, 2015). Uma mudança nesse contexto, exige adaptabilidade, usabilidade e acessibilidade. Tríade indissociável para novas transformações, ações e ressignificações.

De qualquer maneira, a organização curricular e metodológica de uma escola, também depende da equipe gestora. Dito isso, se ver necessário fomentar os recintos escolares com processos formativos referentes ao uso e aplicabilidade das TIC no ensino das diferentes ciências, em especial, da matemática. Entretanto, Costa e Prado (2015, p. 102) tecem que as TIC demandam conhecimentos diversos no sentido de "raciocinar com, criar com e ensinar com tecnologia. Ensinar, não apenas inserindo-as na sala de aula, mas integrando-as e explorando adequadamente o que elas potencializam para o ensino e a aprendizagem em Matemática".

Desta feita, se ver necessidade para propostas de formação continuada. Tais propostas com uso de tecnologias digitais para os professores de Matemática, segundo Santos (2018), possibilitam não somente rupturas de paradigmas ou um somatório de novos saberes. São propostas de formação que também evocam novas possibilidades e outros meios para os alunos conhecerem e aprenderem conteúdos matemáticos. Esse mesmo pensamento corrobora com ideias de Almouloud (2018):

Por meio das TIC, o professor passa do detentor e difusor de conhecimentos para o papel de orientador de equipes engajadas em uma ascensão na qual todo mundo dá o melhor de si mesmo. Cada etapa envolve uma adaptação e novas formas de trabalho, cada vez mais profunda e desestabilizante. (ALMOULOUD, 2018, p. 207) 
Além disso, o uso das TIC nos processos de ensino e aprendizagem condiciona mudanças nos hábitos não apenas do professor, mas também do aluno. Ele passa de ter "um único interlocutor (o professor) para vários interlocutores (sites, equipes de estudantes no mesmo trabalho, o professor em caso de dificuldade específica etc.)" (ALMOULOUD, 2018, p. 207). O que evoca ter o contato com diferentes linguagens e explicações, permitindo maior possibilidade de compreensão dos conceitos abordados. Assim, com o uso de recursos tecnológicos no ensino de matemática,

professores e alunos são beneficiados a partir da capacidade dos aplicativos em demonstrar experiências mais abstratas, em formato visual e ao mesmo tempo dinâmico; outro aspecto positivo é que grande parte dos alunos dispõe de aparelhos celulares smartphone o que facilita a realização das experiências em sala de aula. (RICHTER; WUNSCH; BOTTENTUIT JUNIOR, 2020, p. 14)

Em outras palavras, o uso de tecnologias móveis revolucionou e continua intensificando possibilidades de interações, compartilhamento de informações e principalmente como meio colaborador para a aprendizagem da matemática. São tecnologias, cada vez de menor tamanho, mais acessíveis e com memória que permite integrar uma sala de aula virtual, expandindo desse modo as relações da construção do saber.

Outro aspecto positivo refere-se à instalação de softwares dinâmicos que propiciam visualização e compreensão de conceitos abstratos presentes em alguns conteúdos matemáticos. Acrescenta-se nessa dimensão, outros recursos tecnológicos, a saber, os jogos quizzes, os quais contribuem para o professor explorar situações-problema durante a aula e precede automaticamente com ofeedback.

Ao exposto, é notório existirem inúmeras contribuições das TIC com a coexistência de impasses para integrá-las ao ensino de matemática. No panorama atual, pensando de maneira global e, ao mesmo tempo local, tornou-se mais evidente a relevância e contribuição de recursos tecnológicos para o contato entre professor e aluno e, por conseguinte, manter-se interagindo em busca da troca de conhecimentos.

\section{O ensino de matemática em tempo de pandemia}

O COVID-19 impôs múltiplos desafios a sociedade e, principalmente, a educação. 'Reinventar' é o termo utilizado por muitos, entretanto, será que esta seria a palavra 
apropriada? Antes mesmo do vírus disseminar pelo mundo, as plataformas de aprendizagem virtual, os quizzes, as redes sociais, as salas de reuniões online, entre outros, já estavam disponíveis para os diferentes segmentos da sociedade, inclusive, o da educação.

$\mathrm{Na}$ verdade, trata-se da integração de outros instrumentos que enriquecem perante o ensinar - a comunicação, a difusão da informação e extensão da aprendizagem. Vale deixar claro, que as TIC

Não são os únicos fins nem são as salvadoras da qualidade do ensino. Há, evidentemente, outras alternativas geradoras de interação, de compartilhamento de saberes e questionamentos e que favorecem uma melhor compreensão e, em especial, a aprendizagem Matemática. (SANTOS, 2018, p. 140)

Cabe ao professor, escolher os recursos viáveis para atingir os objetivos traçados em seu planejamento. Ensinar, sempre foi um desafio e requer desenvoltura, engenhosidade e criatividade. Embora, na real situação, percebeu-se a importância de diversificar as estratégias de ensino, a saber, em consonância com as TIC.

Ao que compete o ensino de matemática, antes de qualquer ação ou escolha, o professor deve estar com mente aberta, disposto a aprender em "lidar com recursos tecnológicos e a reconstruir a própria prática docente, aquela que foi construída e consolidada no seu cotidiano escolar muitas vezes sem o uso das TIC" (COSTA; PRADO, 2015, p. 103).

Nessa perspectiva, diversas ações por parte das secretárias municipais, estaduais e pelo MEC, estão fomentando processos formativos que contribuem para o aperfeiçoamento e ampliação do conhecimento acerca das tecnologias e seu uso na prática docente. Uma das propostas do MEC, foi disponibilizar a plataforma AVAMEC com cursos gratuitos aos professores dos diferentes níveis de ensino.

Outro exemplo, são as inúmeras videoconferências disponibilizadas pelas instituições de ensino superior (universidades e institutos) por meio do google meet, zoom, youtube, hangouts, plataforma Cafe e etc, que estão orientando e proporcionando intervenções para incrementar e diversificar o ensino. Em nosso caso, o ensino de matemática.

Após a pandemia, os desafios não deixarão de existir. A educação está intrínseca a elementos complexos e que a cada dia essa complexidade só amplia. Quanto ao ensino de matemática, emerge a necessidade de relacionar os conhecimentos científicos e tecnológicos de modo contributivo e significativo para a aprendizagem. 


\section{As escolhas metodológicas}

Ao buscarmos conhecer como as ações de enfrentamento à pandemia têm implicado no exercício da docência dos professores de matemática, sobretudo em relação ao processo de inserção das TIC, percebemos também a necessidade de adaptar os procedimentos de coleta de dados.

Nossa pesquisa, assume um caráter exploratório visando compreender melhor o contexto em que os professores se inserem, suas principais dificuldades e perspectivas diante deste cenário. Para isso, respeitando as medidas de distanciamento social e principalmente as condições em que os docentes se encontram, com a redobrada carga de trabalho, e pouco tempo disponível para outras interações, optamos por utilizar a plataforma SurveyMonkey que possibilita disponibilizar questionários online, facilitando o compartilhamento das questões e respostas.

Por meio desta plataforma, elaboramos um questionário contendo 09 questões, sendo 02 questões fechadas e 07 questões abertas objetivando respostas dissertativas. Além das informações que caracterizam os participantes da pesquisa, como idade, formação e tempo de atuação, as questões foram direcionadas a conhecer aspectos de sua organização didáticapedagógica frente ao cenário das aulas remotas. As duas questões fechadas, foram elaboradas tomando como base, as normativas do Ministério de Educação (MEC) que regulamentam as atividades remotas.

A pesquisa se delimitou entre os estados de Sergipe, Alagoas e Bahia, obtendo respostas por meio da plataforma online, de 22 professores de matemática do ensino fundamental, com tempo de exercício na docência variando entre 5 e 11 anos. No tópico a seguir onde apresentamos os resultados obtidos, os professores participantes deste estudo serão identificados por códigos (Ex. P1, P2...) visando preservar a identidade nos relatos evocados.

\section{Resultados e análises}

O contexto da educação diante do enfrentamento da pandemia ocasionada pelo COVID-19, causou importantes transformações na prática dos docentes. Isso nos instigou a investigar como as ações de enfrentamento à pandemia do COVID-19, têm implicado no exercício da docência de professores de matemática, sobretudo em relação ao processo de 
inserção das TIC resultando em significativas mudanças na relação desses professores com esses recursos.

Dentre os relevantes aspectos destacados pelos professores participantes da pesquisa, evidenciamos dois obstáculos apontados pelos docentes como principais dificuldades enfrentadas neste momento: a interação entre alunos e professores; a formação docente para o uso das TIC.

A pouca interação entre alunos e professores, é justificada pelos participantes como resultado das dificuldades de acessibilidade dos alunos, o difícil acesso à conexão no acesso desses alunos às atividades disponibilizadas. Isso pode ser observado em alguns relatos.

Não consigo alcançar todos os alunos, pois muitos deles não têm acesso à internet por falta de recursos financeiros familiar ou por residirem em local sem acesso à internet. (P6, Q8)

Há recursos que não podem ser utilizados porque nem todos os alunos conseguem ter acesso à Internet ou a alguns aplicativos, o que dificulta a interação. $(P 7, Q 8)$

Sobre essa situação, o Parecer CNE/CP No 11/2020 destaca que "as limitações na capacidade de implementar atividades não presenciais ao longo no período de isolamento social poderão afetar de modo desigual as oportunidades de aprendizagem dos alunos" (BRASIL, 2020b). Em vista disso, o documento ainda enfatiza a importância de considerar outros fatores, como as diferenças no aprendizado de alunos que possuem auxilio dos pais, apoio remoto das unidades de ensino, motivação, e habilidades para aprender de forma autônoma.

Isso também pode ser identificado em alguns relatos, os professores apontam a dificuldade de interação, mesmo com alunos que possuam acesso a esses recursos, como evidenciado a seguir.

Alunos que são tímidos para perguntar ou pais que não acompanham o filho, [deixando-o em frente ao computador] sem olhar o que estão fazendo, pois tem aluno que está presente, mas jogando e mantendo o som da aula desligado. $(P 15, Q 8)$

Outro ponto difícil é a falta de retorno que há por parte dos alunos. Quase nunca se tem uma mensagem do tipo "professor, não entendi essa parte". Apesar da instituição disponibilizar 2 canais oficiais de comunicação entre aluno e professor, eles quase não utilizam. (P.20, Q8) 


\section{OD DEVIR EDUCAÇÃO \\ ISSN: 2526-849X}

A maior dificuldade é a atenção dos alunos. Poucos mostram atenção. Poucos valorizam a dedicação do professor. (P21, Q8)

Esses relatos caracterizam um dos principais desafios que o contexto educacional tem enfrentado na contemporaneidade, a adaptação ao novo modelo de ensino e de aprendizagem, agravaram situações que há muito tempo já se identificava em sala de aula - as dificuldades de mobilizar o aluno para engajar-se no processo de aprendizagem. Para Almouloud (2018, p. 207), “a aprendizagem nesses ambientes requer uma mobilização pessoal importante, muito mais do que em um ambiente tradicional".

Essa questão, está também relacionada a outra dificuldade destacada pelos docentes frente ao contexto das aulas remotas - a sua formação quanto ao uso das tecnologias. Quando questionados se em algum momento durante sua formação inicial haviam tido contato com as TIC, apenas um professor respondeu que não teve. A maioria teve contato durante o curso de licenciatura, com disciplinas específicas destinadas ao ensino de matemática e uso das TIC. No entanto, nem todos evidenciam apropriação desses conhecimentos para sua prática docente, como podemos identificar nesses relatos.

Tive apenas uma disciplina na graduação, mas o que aprendi na época já nem se aplica nos dias atuais. Por ex. Fazer blog, que hoje pode ser substituído por a página em uma rede social, ou um grupo no WhatsApp atingindo um número ainda maior de pessoas. $(P 14, Q 1)$.

Sim, nas disciplinas novas tecnologias- ciência da computação- somente em atividades sugeridas pelo professor da disciplina. $(P 13, Q 1)$

Sim. Na explanação dos professores, na preparação dos seminários. (P8, Q1)

Neste contexto, as instituições de formação inicial de professores assumem a importante função de subsidiar o contato com as TIC. Para além do mero instrumento ou recurso, mas sobretudo, fomentar o desenvolvimento de competências para que, na futura atuação dos licenciandos, essas TIC sejam utilizadas como uma metodologia de ensino. Dessa forma, também assegurando bom desempenho dos futuros alunos no processo de aprendizagem matemática.

Assim, concordamos com Almouloud (2018), quando enfatiza a importância de uma formação adequada, visando desenvolver tais competências proporcionando aos docentes, 
vivenciar novas e diferentes formas de aprender e ensinar. Segundo o Parecer CNE/CP $\mathrm{N}^{\circ}$ 11/2020, um estudo realizado pela Interdisciplinaridade e Evidências no Debate Educacional (Iede) em parceria com o Instituto Rui Barbosa (IRB), realizado em junho de 2020, também destaca a formação docente como uma das principais dificuldades encontradas pelos docentes, quanto ao uso das TIC. De acordo com o estudo:

Apenas 39\% (trinta e nove por cento) das redes estão oferecendo formações para as atividades não presenciais. Essa situação reforça os resultados de recente pesquisa do Instituto Península, segundo a qual 83\% (oitenta e três por cento) dos professores se sentem despreparados para o ensino virtual e gostariam de receber apoio neste sentido. (BRASIL, 2020b, p.5)

Em nossa pesquisa, apenas um professor destacou que recebeu o convite para participar de um curso de formação. No entanto, ele enfatiza a alta demanda de tempo que tem disponibilizado na elaboração das aulas impossibilitando assumir uma atividade extra. " $A$ coordenação da escola mandou e-mail avisando sobre uns cursos do MEC a distância, mas a questão é: estão tão atarefados planejando e elaborando essas aulas, que não temos nem tempo nem disposição psicológica para aderir a essa formação. (P14, Q9).

Em relação ao ensino de matemática, os professores também destacam algumas dificuldades relacionadas a questões inerentes à disciplina. Os relatos nos evidenciam algumas estratégias desenvolvidas pelos docentes, como alternativas para adaptar o processo de ensino e aprendizagem durante esse contexto. Dentre elas a adaptação do planejamento anual, alterando a organização dos conteúdos, como destacam os professores.

Os conteúdos foram quase todos mudados, porque temos que trabalhar voltado mais a atividades que envolvam interdisciplinaridade e com coisas mais generalista, que não envolvam tanto o conteúdo propriamente dito. $(P 4, Q 7)$

Mudei a ordens de alguns conteúdos - incentivei a construção de jogos tecnológicos no scratch desktop $(P 13, Q 7)$

Mudei o tempo para ministrar os conteúdos, se antes um determinado conteúdo era dado em duas aulas, hoje (durante a pandemia) o conteúdo é abordado em mais aulas que o "normal". (P18, Q7)

Mudou muito. Priorizei o campo dos números e álgebra que não exigem tanta interação. Já conteúdos de geometria eu preciso estar junto dos alunos para ajudar usar os materiais didáticos (régua, compasso, transferidor). Muitos pais, nem sabem que materiais são esses, como eu poderia tentar 
ensinar uma coisa assim dependendo da mediação dos pais? Então, Priorizei a álgebra e números que é mais fácil de explicar e disponibilizar lista de exercícios. $(P 14, Q 7)$

Ao analisarmos esses relatos, evidenciamos que a organização didática pedagógica do professor de matemática, passou por importantes mudanças, sobretudo em relação aos aspectos didáticos da disciplina. A exemplo, a necessidade de pensar em um contexto interdisciplinar destacado pelo professor P4 e a priorização de um determinado campo em relação a outro, como apontou o professor P14, justificando a escolha do campo de números e álgebra, por dispensar a utilização de materiais didáticos que, para esse professor seriam indispensáveis no campo geométrico.

Em contrapartida, outro professor optou por adentrar no campo geométrico por entenderem que as TIC poderiam fomentar o ensino destes conteúdos, sinalizando a utilização de softwares como destaca o professor P17.

Mudei a ordem dos conteúdos, adequei para aqueles que as TIC poderiam ter um maior auxílio. Exemplo. Função, geométrica. [...] Notei que por mais que seja difícil, é necessário. $O$ auxílio por exemplo do Geogebra está facilitando e levando um aprendizado. (P17, Q7, Q9)

Sobre esse aspecto, o Parecer CNE/CP N $05 / 2020$, destaca que "a legislação educacional e a própria BNCC admitem diferentes formas de organização de trajetória escolar, sem que a segmentação anual seja uma obrigatoriedade" (BRASIL, 2020a, p.4). Desta forma, o documento garante autonomia na organização didática do professor, possibilitando a realização destas e outras alterações, desde que assegure o alcance dos objetivos de aprendizagem estabelecidos pelos currículos de acordo com cada nível de ensino.

Como possibilidades de atividades pedagógicas a serem desenvolvidas pelos professores durante esse período de aula remotas, o Parecer CNE/CP N 05/2020 apresenta algumas sugestões. No processo de coleta de dados, apresentamos essas sugestões aos docentes e questionamos se algumas delas estavam sendo executadas, as respostas são apresentadas na próxima Tabela.

Atividades pedagógicas realizadas pelos professores participantes.

\begin{tabular}{l|c}
\hline \multicolumn{1}{c|}{ Atividades pedagógicas sugeridas no Parecer CNE/CP N $\mathbf{0 5 / 2 0 2 0}$} & $\begin{array}{c}\text { Número de } \\
\text { professores } \\
\text { adeptos }\end{array}$ \\
\hline $\begin{array}{l}\text { Utilização, quando possível, de horários de TV aberta com programas educativos para } \\
\text { adolescentes e jovens. }\end{array}$ & 3
\end{tabular}


Distribuição de vídeos educativos, de curta duração, por meio de plataformas digitais, mas sem a necessidade de conexão simultânea, seguidos de atividades a serem realizadas com a supervisão dos pais.

Realização de atividades online síncronas de acordo com a disponibilidade tecnológica; oferta de atividades online assíncronas de acordo com a disponibilidade tecnológica;

Estudos dirigidos, pesquisas, projetos, entrevistas, experiências, simulações e outros; realização de testes online ou por meio de material impresso, entregues ao final do período de suspensão das aulas.

Fonte: Dos autores (2021)

Além destas, outras atividades e estratégias estão sendo desenvolvidas pelos professores, como gravações de vídeos, aulas online via Streaming no Zoom, Google Meet, e ambientes virtuais da própria escola. Utilização de softwares como o GeoGebra, Kahoot na elaboração de quis matemáticos, scratch desktop e jogos online.

Como meio utilizado para estimular e orientar os alunos nos estudos, os professores destacam o uso das redes sociais, principalmente, o WhatsApp utilizado por $77 \%$ dos docentes, seguido do Google sala de aula empregado por 50\% deles, YouTube 45\%, e outras redes como Instagram e Facebook utilizados por $18 \%$ dos participantes.

Neste contexto, também identificamos relatos apontando mudanças nas concepções dos professores, em relação à inserção das TIC no processo de ensino de matemática. Além dos que já reconheciam a importância desses recursos como instrumentos contributivos ao processo de ensino e aprendizagem, houve também relatos apontando novas perspectivas em relação a esse processo de inserção das TIC em sala de aula.

Minha concepção mudou a ponto de quando retornarmos as aulas presenciais buscarei inserir de forma mais ativa as tecnologias na minha prática pedagógica. $(P 7, Q 9)$

Essa situação que estamos vivenciando me fez parar para pensar e aprender novas formas de abordagens. Esse momento me proporcionou estudar e desenvolver arquivos de interação com o conteúdo através de apresentações do powerpoint e shockwave. $(P 20, Q 9)$

Eu já utilizava em sala com uma certa frequência, mas percebi que teríamos menos dificuldade se o uso da tecnologia fosse uma constante. (P19, Q9)

No entanto, para grande parte dos professores embora reconheçam a importância da inserção das TIC na prática pedagógica, durante o ensino presencial, também sinalizam para 


\section{ODEVIR EDUCAÇÃO}

ISSN: 2526-849X

as dificuldades encontradas também neste contexto, a falta de infraestrutura adequada para utilização desses recursos. Em seus relatos, esses professores nos apontam que:

Agora eu fico pesquisando (porque estou meio condicionada a isso) $e$ percebo softwares que me ajudariam muito, mas em contrapartida a situação da minha escola não sei quando irá mudar. Meus alunos nem todos tem acesso a computador e internet, e nem minha escola possui laboratório. (P14, Q9)

Eu já tinha essa visão e sempre fui aberta ao uso das tecnologias para o ensino de matemática, percebo nesse momento que essas tecnologias ainda não estão disponíveis para a maioria dos alunos brasileiros e isso torna o seu uso muito mais difícil. (P14, Q9)

Em suma, são relatos que evocam importantes reflexões acerca do contexto em que os sistemas de ensino se inserem, frente às medidas de distanciamentos sociais ocasionados pela pandemia do Covid-19. Em relação ao ensino de matemática, os dados nos revelam um cenário de desafios a serem superados, da mesma forma, sinalizam para perspectivas de possíveis mudanças de concepções dos docentes em relação à inserção das TIC como instrumentos contributivos no processo de ensino e aprendizagem.

\section{Considerações finais}

Neste artigo, tivemos por objetivo, conhecer de que forma as ações de enfrentamento à pandemia impactaram no exercício da docência dos professores de matemática. Buscando identificar, como essas ações implicaram na sua prática docente, sobretudo, em relação à inserção das Tecnologias de Informação e Comunicação. Assim como, quais são suas principais estratégias desenvolvidas por eles, ao atender as recomendações oriundas de normativas que regulamentam o ensino básico nesse período de aulas remotas.

O contexto imposto pela pandemia também nos mostrou ser necessário adaptar nossos procedimentos metodológicos, respeitando as medidas de distanciamento social e para isso, nos valendo dos recursos tecnológicos para alcançarmos os 22 professores de matemática participantes deste estudo. Diante disso, nossas escolhas teóricas e metodológicas, se mostraram eficientes nos possibilitando atender nosso objetivo neste estudo respondendo as inquietações que nortearam este trabalho.

A primeira delas, nos revelam alguns aspectos das dificuldades encontradas pelos docentes nos processos de ensino e aprendizagem da matemática, neste cenário pandêmico. 
Para os professores participantes, são dois os principais obstáculos destacados como uma defasagem em sua formação docente: pouca interação com o aluno atribuído às dificuldades de acessibilidade dos estudantes e despreparo do próprio professor para usar TIC.

Tais dificuldades implicaram na reorganização didática desses professores remetendoos a adaptar seu planejamento anual de acordo com as atuais necessidades. Dentre as principais adaptações, destacam-se a reorganização dos conteúdos e a adaptação das atividades, levando em consideração, para isso, as dificuldades que os alunos possam vir a ter, ao desenvolver tais atividades, sem a mediação do professor.

Os dados também respondem a outra das questões investigadas nesta pesquisa, revelando quais são as TIC que estão sendo utilizadas como estratégias de ensino nas aulas à distância. Além das videoaulas gravadas e disponibilizadas pela grande maioria dos docentes, também estão sendo utilizados alguns softwares e aplicativos, bem como, a utilização das redes sociais, como um canal de comunicação entre os docentes e os alunos.

O estudo também nos revelou indícios de mudanças nas concepções dos professores, em relação ao uso das tecnologias de informação e comunicação, com o retorno das aulas presenciais. São apontados por eles, como perspectivas futuras, possíveis articulações entre outras metodologias de ensino da matemática e as TIC como uma estratégia contributiva nos processos de ensino e aprendizagem, também, no ensino presencial.

Por fim, enquanto pesquisadores do campo da Educação Matemática, esperamos com esta pesquisa, fomentar o campo de estudo sobre a temática. Da mesma forma, fornecermos perspectivas e direcionamentos que subsidiem o surgimento de Políticas Públicas destinadas a atender a demanda dos processos de ensino e aprendizagem tanto no cenário da pandemia, quanto nas implicações geradas em um cenário pós-pandemia.

\section{Referências}

ALMOULOUD, Saddo Ag. Integração de tecnologias digitais no ensino: reflexões sobre práticas e formação de professores. Revista Debates em Educação, v. 10, n. 22, Maceió, 2018.

BORBA, Marcelo de Carvalho. Informática e educação matemática. Belo Horizonte. Autentica Editora, 2015.

BORBA, Marcelo de Carvalho; SCUCUGLIA, Ricardo; GADANIDIS, George. Fases das tecnologias digitais em educação matemática: sala de aula e internet em movimento. 1. ed. Belo Horizonte: Autêntica Editora, 2015. 


\section{OD DEVIR EDUCAÇÃO \\ ISSN: 2526-849X}

BRASIL. Conselho Nacional de Educação. Orientações educacionais para a realização de aulas e atividades pedagógicas presenciais e não presenciais no contexto da pandemia. CNE/CP $\quad \mathrm{N}^{\circ} \quad 11 / 2020$. Disponível em: <http://portal.mec.gov.br/index.php?option=com_docman\&view=download\&alias=148391pcp011-20\&category_slug=julho-2020-pdf\&Itemid=30192>. Acessado em 19 jul. 2020a.

BRASIL. Conselho Nacional de Educação. Reorganização do calendário escolar e da possibilidade de cômputo de atividades não presenciais para fins de cumprimento da carga horária mínima anual, em razão da pandemia da COVID-19. CNE/CP N 5/2020. Disponível

em: $<$ http://portal.mec.gov.br/index.php?option=com_docman\&view=download\&alias=14501 1 -pcp005-20\&category_slug=marco-2020-pdf\&Itemid=30192 >. Acessado em 20 jul. 2020 b.

COSTA, Nielce Meneguelo Lobo; PRADO, Maria Elisabette Brisola Brito. A integração das tecnologias digitais ao ensino de matemática: desafio constante no cotidiano. Revista Perspectivas da Educação Matemática, v. 8, n. 16, Mato Grosso do Sul, 2015.

MORIN, Edgar. Introdução ao pensamento complexo. Editora Sulina, 2015.

RICHTER, Ana Patrícia Henzel; WUNSCH, Luana Priscila; BOTTENTUIT JUNIOR, João Batista. Da prática aos recursos tecnológicos: considerações acerca da matemática no ensino médio. Revista Interfaces Científicas - Educação, v. 9, n. 2, 2020.

SANTOS, José Elyton Batista. Do pó de giz aos bits: cartografando os processos de adesão e inserção do computador interativo no ensino de matemática. Dissertação (Mestrado em Ensino de Ciências e Matemática) - Universidade Federal de Sergipe, São Cristóvão, 2018.

Recebido em: 07/07/21

Aprovado em: 25/08/21

Revista Devir Educação, Lavras-MG. Edição Especial, p.287-302, Set./2021. 